\title{
"I Did Not Choose to Be Obese"-Experiences of Stigma among Market Women in Kaneshie, Ghana
}

\author{
Mildred Arday¹, Virtue Fiawokome De-Gaulle2*, Kofi Agyabeng33, Richmond Aryeetey \\ ${ }^{1}$ Department of Population and Family Planning, School of Public Health, University of Ghana, Legon, Accra, Ghana \\ ${ }^{2}$ School of Medicine, Malaria Research Capacity Development (MARCAD), University of Health and Allied Sciences, \\ Volta Region, Ho, Ghana \\ ${ }^{3}$ Department of Biostatistics, School of Public Health, University of Ghana, Legon, Accra, Ghana \\ Email: ^nunana2009@live.com, mabakajackson@yahoo.com, kagyabeng480@gmail.com, raryeetey@ug.edu.gh
}

How to cite this paper: Arday, M., DeGaulle, V.F., Agyabeng, K. and Aryeetey, R. (2020) "I Did Not Choose to Be Obese"Experiences of Stigma among Market Women in Kaneshie, Ghana. Open Access Library Journal, 7: e6281.

https://doi.org/10.4236/oalib.1106281

Received: March 29, 2020

Accepted: May 6, 2020

Published: May 9, 2020

Copyright $\odot 2020$ by author(s) and Open Access Library Inc.

This work is licensed under the Creative Commons Attribution International License (CC BY 4.0).

http://creativecommons.org/licenses/by/4.0/

\begin{abstract}
Excess body fat is associated with impaired physical and socio-emotional health outcomes. There is limited evidence on stigma and discrimination associated with overweight and obesity in developing country settings like Ghana where the rate of overweight is rapidly increasing. This current study explored the experiences of obesity-related stigma and discrimination among adult female vendors in the Kaneshie Market in Accra, Ghana. Employing a mixed concurrent method, both qualitative and quantitative data were collected. Quantitatively, about half (56\%) of the survey respondents were obese, however, most of them misperceived their weight. Using Pearson Chi-square test of association, respondent age, marital status, educational level, ethnicity and parity were significantly associated with BMI status. Multiple (adjusted) ordered logistic regression model showed age, ethnicity and marital status and parity to be significant demographic characteristics predictive of weight status. Single women had about four times lesser odds of having a higher weight status compared to those who were either married, divorced/separated/widowed, or cohabiting. Educational status was not significantly associated with BMI status in adjusted model. The qualitative findings revealed derogatory name calling, limitations to use of public spaces, and denial of opportunities as stigmatizing and discriminatory attitudes experienced by obese respondents.
\end{abstract}

\section{Subject Areas}

Public Health 


\section{Keywords}

Obesity, Stigma, Market Women, Kaneshie, Ghana

\section{Introduction}

Overweight is a condition of excess adipose tissue accumulation that impairs health [1]. Globally, more than 1.9 billion adults are overweight, and over 650 million are obese [1]. Together, obesity and overweight are considered a global epidemic, necessitating intensive preventive and control actions [2]. Although overweight and obesity prevalence is higher in developed countries [3] [4] [5], prevalence in developing countries like Ghana, is currently high and increasing rapidly [6] [7] [8] [9]. In Ghana, 2014 Demographic and Health Survey (GDHS) showed that 40 percent of Ghanaian women are overweight or obese [10] and are the highest among urban-dwelling females [11] [12].

Overweight and obesity-related stigma involves social devaluation and denigration of people perceived to have excess body weight. This perception leads to negative stereotyping, and discrimination [13]. This kind of stigma is usually drawn from the notion that the condition is changeable and controllable [14]. In essence, excess weight gain is subconsciously construed as a person's choice with stigmatization being used, deliberately or unconsciously, as a means to inspire them to adopt improved behaviors [15]. Stigma and discrimination towards overweight persons pose numerous consequences for their psychological and physical health [16] [17] [18] with depression, low self-esteem, eating disorders and low work productivity being some of the adverse effects [16] [19]. While the somatic health aspects of overweight have been well studied in Ghana, there is limited evidence on the links between being overweight and socio-emotional health of Ghanaians [20]. This study was, therefore, carried out to explore the perceptions and experiences of obesity and overweight related stigma among female vendors in the Kaneshie market in Accra, Ghana.

\section{Methods}

\section{Study Design}

This was a concurrent mixed methods study that entailed the collection of both qualitative and quantitative data cross-sectionally, with the qualitative component employing a phenomenology approach. This study design enabled the collection of different but complimentary data on factors associated with obesity as well as the perceptions and lived experiences of stigma among the female vendors in the Kaneshie Market. Questionnaires were used to collect the quantitative data, whilst in-depth interview (IDI) guides were used for interviews in the qualitative study.

\section{Study Area and Population}

The study was carried out at the Kaneshie Market, a suburb of Accra, Ghana. 
The main market is a three-storey with about 2345 well demarcated stalls accommodating about 7000 vendors trading in various commodities. The study population comprised of female vendors of reproductive age 18 years and above, selling in demarcated stalls within the market storey building.

\section{Data collection procedure}

Systematic random sampling was used to select survey respondents. A survey sample size of 266 was determined using Cochran's formula (1963-1975) for estimating sample sizes for cross-sectional studies.

The sample size was calculated based on Cochran's formula (1963-1975). A prevalence of $22 \%$ was used as the prevalence of obesity among women in Accra based on findings from the study by Ofori-Asenso, Agyeman, Laar, \& Boateng, (2016)

$$
N=\frac{z^{2} p(1-p)}{d^{2}}
$$

$N=$ the required sample size.

$Z=\mathrm{Z}$ statistic for $95 \%$ level of confidence (1.96).

$d=$ Precision at a $P$-value of 0.05 .

$P=$ Expected prevalence or proportion of overweight and obesity among women.

The sample size is therefore

$$
\frac{1.96^{2} \times 0.22(1-0.22)}{0.05^{2}}
$$

$n=263$.

The sample size for the study was therefore approximated to 266 respondents.

The total number of stalls $(n=2345)$ in the market was divided by the calculated sample size of 266 to obtain a sampling interval of nine (9). A ballot was cast to determine which floor of the storey building the sampling will commence from with an interval of eight stalls skipped before sampling the next respondent. At each selected stall, one eligible respondent (18 years and above who works in the sampled stall) was invited to participate in the study.

With reference from studies conducted to assess obesity and stigma, a quantitative data collection tool (structured questionnaire) was designed to elicit responses on socio-demographic characteristics, household assets and wealth, perceptions of overweight and obesity as well as stigma. The tool was pre-tested among market women in Madina Market because the women there are comparable to the sample of correspondents in the main data collection site Kaneshie Market. Necessary modifications were effected based on findings from the pre-test. Using an interviewer-administered procedure, the questionnaires were used to elicit responses from study respondents. In addition, a weighing scale (TANITA, model TBF-300A, TANITA Corporation, USA) and stadiometer (Detecto model, China) were used to collect weight and height data. Body Mass Index (BMI) was calculated for each survey respondent as a ratio of weight measured in kilograms and a square of the height, in metres. For this study, a person was classified as normal weight, overweight or obese if her BMI is from 
$18.5-24.9,25.0-29.9$, or $>30.0$ respectively.

An interview guide was used to collect the qualitative data. The interview guides elicited information on the respondent's perception about the causes of obesity, how they perceive their weight status, and lived experiences stigma due to their weight status. Obese, overweight and normal weighted market women who participated in the quantitative study were purposefully selected and interviewed. After interviewing ten of the market women, a saturation point was reached, with the information from the interviews being similar.

\section{Analysis}

The Pearson Chi-square statistic was used to test association between weight status (BMI) and socio-demographic characteristics. Ordered logistic regression model was used to determine the effect of the demographic factors on respondents' BMI. All statistical analyses were tested at $p<0.05$ significance level. All the in-depth interviews were audio-recorded in addition to hand written notes. The recorded in-depth interviews were transcribed verbatim after which they were analyzed using thematic analysis approach by two post-graduate persons trained in qualitative data analysis. First, codes were generated using the study objectives, interview guides, and recurring findings in the transcripts. Similar sub-codes were merged to form bigger codes and subsequently themes. Employing manual thematic analysis, a matrix of the themes was created in Microsoft Word and quotes were categorized under the various themes.

\section{Results}

Socio-Demographic characteristics of women vendors in Kaneshie market

The study sampled 266 women from the Kaneshie market with over half (55.3\%) of them aged between 35 to 55 years. About a third of the women indicated Junior High School or Form 4 as their highest educational level completed; $26.3 \%$ were Senior High School or vocational school graduates. University graduates were just 6.4\%. The respondents were mostly Ga-adangbes (45.5\%), Akans (33.8\%), Ewes (18.1\%) and Northerners (2.6\%). About three-quarters $(75.1 \%)$ of the study respondents were married with single women making up about $10.9 \%$ All the respondents were traders selling merchandise like food stuff (44.0\%), personal effects (35\%) or rendering services like dressmaking or hairdressing (9.8\%). Majority of them respondents were mothers. Overall, BMI assessments showed that $150(56.4 \%)$ were obese $72(27.1 \%)$ being overweight and 44 (16.5\%) had normal weight status (Table 1 ).

Association between demographic characteristics of market women at Kaneshie and their body mass index

Using Pearson Chi-square test of association, respondent age, marital status, educational level, ethnicity and parity were significantly associated with BMI status $(p<0.05)$. From the multiple (adjusted) ordered logistic regression model, age, ethnicity and marital status were the significant demographic cha- 
Table 1. Socio-demographic characteristics of women vendors in Kaneshie market.

\begin{tabular}{|c|c|c|}
\hline Characteristics & Frequency & Percentage \\
\hline \multicolumn{3}{|l|}{ Age in years } \\
\hline $18-35$ & 83 & 31.2 \\
\hline $36-55$ & 147 & 55.3 \\
\hline $56-67$ & 36 & 13.5 \\
\hline \multicolumn{3}{|l|}{ Highest educational level } \\
\hline None & 37 & 13.9 \\
\hline Primary & 46 & 17.3 \\
\hline JHS/Middle school & 96 & 36.1 \\
\hline SHS/Vocational & 70 & 26.3 \\
\hline Tertiary $^{1}$ & 17 & 6.4 \\
\hline \multicolumn{3}{|l|}{ Ethnicity } \\
\hline Akan & 90 & 33.8 \\
\hline Ga-adangbe & 121 & 45.5 \\
\hline Ewe & 48 & 18.1 \\
\hline Northerner & 7 & 2.6 \\
\hline \multicolumn{3}{|l|}{ Current marital status } \\
\hline Single & 29 & 10.9 \\
\hline Married & 144 & 75.1 \\
\hline Divorced/Separated/widowed & 57 & 21.4 \\
\hline Cohabiting & 36 & 13.5 \\
\hline \multicolumn{3}{|l|}{ Income earning activity } \\
\hline Food & 117 & 44.0 \\
\hline Personal effects & 93 & 35.0 \\
\hline Utensils/Plastics & 30 & 11.3 \\
\hline Services & 26 & 9.8 \\
\hline \multicolumn{3}{|l|}{ Household Head } \\
\hline Respondent & 108 & 40.6 \\
\hline Spouse & 106 & 39.9 \\
\hline Both & 45 & 16.9 \\
\hline Parent & 7 & 2.6 \\
\hline \multicolumn{3}{|l|}{ Parity } \\
\hline No child & 41 & 15.4 \\
\hline $1-3$ & 118 & 44.4 \\
\hline$\geq 4$ & 107 & 40.2 \\
\hline \multicolumn{3}{|l|}{ Body Mass index (BMI) } \\
\hline Normal $\left(\mathrm{BMI}<25 \mathrm{~kg} / \mathrm{m}^{2}\right)$ & 72 & 27.1 \\
\hline Overweight $\left(25 \mathrm{~kg} / \mathrm{m}^{2} \leq \mathrm{BMI}<30 \mathrm{~kg} / \mathrm{m}^{2}\right)$ & 150 & 56.4 \\
\hline Obese $\left(\mathrm{BMI} \geq 30 \mathrm{~kg} / \mathrm{m}^{2}\right)$ & 44 & 16.5 \\
\hline
\end{tabular}

SD: Standard deviation, BMI: Body Mass Index, JHS: Junior High School, SHS: Senior High School. ${ }^{1}$ Tertiary $=$ training college, polytechnic, University. 
racteristics predictive of weight status of respondents $(p<0.05)$. In the multivariable logistic regression, older women had higher odds of higher weight status compared to younger women. Single women had more than four times less odds of having a higher weight status compared to those who were either married, or divorced/separated/widowed, or cohabiting (Table 2).

Table 2. Association between demographic characteristics of market women at Kaneshie and body weight.

\begin{tabular}{|c|c|c|c|c|c|c|c|}
\hline \multirow[t]{2}{*}{ Demographic characteristics } & \multicolumn{3}{|c|}{ Body Mass Index Status } & \multirow{2}{*}{$\begin{array}{c}\text { Chi-square } \\
P \text {-value }\end{array}$} & \multicolumn{3}{|c|}{ Adjusted } \\
\hline & Normal & Overweight & Obese & & $\mathrm{aOR}$ & $95 \% \mathrm{CI}$ & $P$-value \\
\hline Age in years & & & & $<0.001^{\star * *}$ & & & $<0.001^{* * *}$ \\
\hline $18-35$ & $26(31.33)$ & $29(34.94)$ & $28(33.73)$ & & ref & & \\
\hline $36-55$ & $15(10.2)$ & $33(22.45)$ & $99(67.35)$ & & 4.28 & $1.98-9.24$ & \\
\hline $56-67$ & $3(8.33)$ & $10(27.78)$ & $23(63.89)$ & & 5.09 & $1.71-10.14$ & \\
\hline Educational level & & & & $0.012^{*}$ & & & 0.611 \\
\hline None & $2(5.41)$ & $12(32.43)$ & $23(62.16)$ & & ref & & \\
\hline Primary & $6(13.04)$ & $9(19.57)$ & $31(67.39)$ & & 1.2 & $0.46-3.12$ & \\
\hline JHS/Form 4 & $14(14.58)$ & $22(22.92)$ & $60(62.5)$ & & 0.89 & $0.39-2.03$ & \\
\hline SHS/Vocational & $20(28.57)$ & $21(30)$ & $29(41.43)$ & & 0.59 & $0.23-1.50$ & \\
\hline Tertiary & $2(11.76)$ & $8(47.06)$ & $7(41.18)$ & & 0.87 & $0.25-3.02$ & \\
\hline Ethnicity & & & & $0.027^{*}$ & & & $0.024^{*}$ \\
\hline Akan & $21(23.33)$ & $28(31.11)$ & $41(45.56)$ & & ref & & \\
\hline Ga-dangbe & $12(9.92)$ & $30(24.79)$ & $79(65.29)$ & & 2.13 & $1.18-3.84$ & \\
\hline Ewe & $11(22.92)$ & $13(27.08)$ & $24(50)$ & & 1.31 & $0.62-2.78$ & \\
\hline Northerner & $0(0)$ & $1(14.29)$ & $6(85.71)$ & & 8.11 & $1.04-15.98$ & \\
\hline Marital status & & & & $<0.001^{\star * *}$ & & & $0.004^{* *}$ \\
\hline Single & $17(58.62)$ & $6(20.69)$ & $6(20.69)$ & & ref & & \\
\hline Married & $16(11.11)$ & $42(29.17)$ & $86(59.72)$ & & 6.87 & $2.06-15.89$ & \\
\hline Divorced/Separated/widow & $6(10.53)$ & $10(17.54)$ & $41(71.93)$ & & 8.59 & $3.01-20.7$ & \\
\hline Cohabiting & $5(13.89)$ & $14(38.89)$ & $17(47.22)$ & & 4.41 & $1.28-11.26$ & \\
\hline Household Head & & & & 0.120 & & & 0.221 \\
\hline Yourself & $19(17.59)$ & $31(28.7)$ & $58(53.7)$ & & ref & & \\
\hline Spouse & $14(13.21)$ & $31(29.25)$ & $61(57.55)$ & & 1.82 & $0.89-3.74$ & \\
\hline Both & $8(17.78)$ & $7(15.56)$ & $30(66.67)$ & & 2.47 & $1.02-5.95$ & \\
\hline Parent & $3(42.86)$ & $3(42.86)$ & $1(14.29)$ & & 1.59 & $0.28-9.18$ & \\
\hline Trade & & & & 0.823 & & & 0.221 \\
\hline Food & $23(19.66)$ & $31(26.5)$ & $63(53.85)$ & & ref & & \\
\hline Personal effects & $12(12.9)$ & $28(30.11)$ & $53(56.99)$ & & 0.9 & $0.49-1.64$ & \\
\hline Utensils/Plastics & $5(16.67)$ & $8(26.67)$ & $17(56.67)$ & & 1.16 & $0.5-2.72$ & \\
\hline Services & $4(15.38)$ & $5(19.23)$ & $17(65.38)$ & & 2.93 & $0.98-8.71$ & \\
\hline
\end{tabular}

BMI = body mass index. Normal $\left(\mathrm{BMI}<25 \mathrm{~kg} / \mathrm{m}^{2}\right)$, Overweight $\left(25 \mathrm{~kg} / \mathrm{m}^{2} \leq \mathrm{BMI}<30 \mathrm{~kg} / \mathrm{m}^{2}\right)$, Obese $\left(\mathrm{BMI} \geq 30 \mathrm{~kg} / \mathrm{m}^{2}\right)$, (\%) represents row percentage, aOR: Adjusted Odds Ratio, $p$-value notation: ${ }^{* *} p<0.001,{ }^{* *} p<0.01,{ }^{*} p<0.05$, $:$-value was estimated from the one-way ANOVA test. ref: reference category. SD: Standard deviation, JHS: Junior High School, SHS: Senior High School. 


\section{Women's Perception of weight status}

Misperception about body weight was observed commonly among the respondents. Out of the 266 respondents, 56.39\% (150) were obese, yet $56.45 \%$ (105) of them perceived themselves to be overweight. Majority (60\%) of the women who thought they had normal weight wanted to gain some more weight while $59.1 \%$ of those who thought they were overweight wanted to maintain it. Conversely, $73.3 \%$ of women who perceived themselves as obese wanted to lose some weight. One-third (34.3\%) of the respondents with a perception of normal weight wanted to gain or maintain their weight in order to be socially accepted. Those who thought they were overweight or obese and wanted to maintain or lose weight were motivated by the need to have better health (Table 3 ).

\section{Derogatory name callings}

Derogatory name calling is a common stigmatizing attitude that overweight and obese people experience. Women with normal weight mentioned different names by which they call overweight and obese persons and this was confirmed by obese respondents as they also mentioned names they are tagged with. Overweight and obese persons expressed dislike, shame and anger when they are called those names.

Table 3. Women's body weight, weight preferences and weight perception by other people.

\begin{tabular}{|c|c|c|c|c|}
\hline \multirow{2}{*}{ Responses } & \multicolumn{4}{|c|}{ Perceived body weight } \\
\hline & Normal (\%) N = 35 & Over weight (\%) $\mathrm{N}=186$ & Obese (\%) $N=45$ & Total (\%) N $=266$ \\
\hline \multicolumn{5}{|l|}{ Weight groups of respondents } \\
\hline $\operatorname{Normal}\left(B M I<25 \mathrm{~kg} / \mathrm{m}^{2}\right)$ & $20(57.14)$ & $24(12.9)$ & $0(0)$ & $44(16.54)$ \\
\hline Overweight $\left(25 \geq B M I<30 \mathrm{~kg} / \mathrm{m}^{2}\right)$ & $10(28.57)$ & $57(30.65)$ & $5(11.11)$ & $72(27.07)$ \\
\hline Obese $\left(B M I \geq 30 \mathrm{~kg} / \mathrm{m}^{2}\right)$ & $5(14.29)$ & $105(56.45)$ & $40(88.89)$ & $150(56.39)$ \\
\hline \multicolumn{5}{|l|}{ Body weight preference } \\
\hline Desire to Lose weight & $4(11.43)$ & $64(34.41)$ & $33(73.33)$ & $101(37.97)$ \\
\hline Desire to Gain weight & $21(60)$ & $12(6.45)$ & $1(2.22)$ & $34(12.78)$ \\
\hline Wants to maintain & $10(28.57)$ & $110(59.14)$ & $11(24.44)$ & $131(49.25)$ \\
\hline \multicolumn{5}{|l|}{ Reasons for weight preference } \\
\hline Societal acceptance & $12(34.29)$ & $47(25.41)$ & $14(32.56)$ & $73(27.76)$ \\
\hline Health consideration & $10(28.57)$ & $61(32.97)$ & $19(44.19)$ & $90(34.22)$ \\
\hline Self-satisfaction and confidence & $9(25.71)$ & $51(27.57)$ & $8(18.6)$ & $68(25.86)$ \\
\hline Meet media's ideal look description & $4(11.43)$ & $26(14.05)$ & $2(4.65)$ & $32(12.17)$ \\
\hline \multicolumn{5}{|l|}{ People's view about your body weight } \\
\hline Acceptable/ comfortable & $19(54.29)$ & $127(69.78)$ & $17(37.78)$ & $163(62.21)$ \\
\hline Too fat & $2(5.71)$ & $44(24.18)$ & $28(62.22)$ & $74(28.24)$ \\
\hline Too slim & $14(40)$ & $11(6.04)$ & $0(0)$ & $25(9.54)$ \\
\hline
\end{tabular}


"we call such people obolo or bosa (a big marine fish), such people have different names, others also describe them as obigi and when they call them such names we see that they are not happy and it bothers them" (IDI, 38-year-old normal weight woman).

"they say obolo, okesie, big size and stuff like that, it is annoying but sometimes you just have to ignore them and go your way" (IDI, 25-year-old obese woman).

\section{Denial of jobs due to overweight/obese}

Overweight and obesity were documented as barriers to acquiring certain jobs. Some respondents recounted how they were denied some job opportunities because of their weight and body size. Instances were cited of how the media prefers people with slim personality as opposed to overweight or obese persons.

"because of my weight I was supposed to run a TV show in which I started but along the line when I was looking for sponsorship I was told because of my size they can't put in their money because it wouldn't fetch money so the best thing for me to do is to go on a diet so that I will be very slim and good looking meaning because of my weight I wasn't good looking. Those were some of the reasons why I left the media (IDI, a 36-year-old obese woman).

\section{Withdrawal from social activities due to stigmatizing attitudes}

Feelings of shame, anger, and self-pity are some of the sentiments obese women expressed when they are subjected to discriminatory or stigmatizing behaviors. Overweight and obese persons described how embarrassing and annoying it is when they are stared at or talked about in the streets.

"Sometimes you will be walking in town and you will see that everybody's attention is on you and sometimes you are wondering what they are looking at only to find out that they are looking at you and you ask yourself why me? Or when you are walking with your friends and they pass comments about your weight, it is not nice, it is embarrassing." (IDI, a 36-year-old obese woman).

\section{Discussion}

Stigma and discrimination toward obese persons are ubiquitous, making it a universal public health concern [1]. Perceptions that overweight and obese persons are lazy, lack self-control and are responsible for their weight further exacerbates the problem. This study investigated the perceptions and stigmatization associated with overweight and obesity among women of reproductive age living in urban area in Ghana. Findings from the study revealed different forms of expression of stigma including derogatory name calling, discrimination regarding use of public services (transportation), exposure to gossiping and being stared at, as well as being blamed for being lazy and eating too much.

Overweight women in this study misperceived their weight status as normal weight although they indicated that people consider them to be overweight. This misconception about body weight could be because the women are in denial of their unhealthy weight, or do not want to be labelled as obese. This finding is not 
surprising as previous studies have reported women to be more likely to underestimate their body weight [21] [22] [23] [24]. Most of the obese respondents expressed the desire to lose weight with a few desiring to maintain their weight. However, majority of the overweight women preferred to maintain their weight. Obesity and overweight used to be associated with wealth, beauty and good health in most African countries including Ghana [25] [26], this cultural perception could explain why some respondents preferred to maintain their body weight despite being obese or overweight. Also, obese respondents may be aware of the health implications of their weight, hence their desire to lose weight. Obese and overweight respondents engaged in various activities such as exercising, using medications and even starvation to facilitate weight loss. However, contrary to our findings, a study conducted in a rural village in South Africa revealed that overweight and obese women were unconcerned about their weight and most of them did not want to lose weight [27].

Normal weight respondents in this study were of the opinion that obese and overweight persons are to blame for their weight as they associated their weight to excessive eating, consumption of fatty foods, physical inactivity. Relatedly, a systematic review by Sikorski and colleagues on the stigma of obesity in the general public and its implications for public health reported that although the public acknowledged the multi causality of obesity to some extent, causes that are within the individual's control like physical inactivity and consumption of fatty foods were named most frequently in population surveys [28]. Therefore, overweight and obese persons are blamed for their weight and body sizes. In opposition, obese and overweight persons assigned their weight gain to parity and heredity with a similar finding in a study by Gonçalves and colleagues where obese adolescents attributed their weight to hereditary [29]. Overweight and obese individuals who experience weight stigmatization have higher rates of depression, anxiety, and social isolation [15]. Overweight and obese persons in this study also revealed excluding themselves from social gatherings because of the stigma and discrimination and expressed sentiments of anger, shame and embarrassment when they are subjected to such treatments. These study findings affirm the fact stigma and discrimination toward obese persons are universal. It is therefore imperative that health education and promotion be intensified on the negative effects of these acts of discrimination and stigma towards obese people. Emphasis should be laid on encouraging obese and overweight persons to endeavor to lose weight rather than stigmatize or discriminate against them.

\section{Limitation}

The translation of some English words such as stigma to the local dialect $\mathrm{Ga}$ and Twi may have led to some missing emphasis on the translated words.

\section{Conclusion}

Majority of the women sampled in the quantitative aspect of the study were ob- 
ese. While some of them wanted to lose weight, others also preferred their weight status they believe it was fashionable. Respondents believed obesity is caused by excessive eating, consuming fatty foods and physical inactivity. These perceived causes of obesity influenced the stigma meted out on the obese/overweight persons as they were blamed for their condition.

\section{Ethics Approval and Consent to Participate}

Ethical approval was obtained from the Ghana Health Service Ethical Review Committee (GHS-ER: 16/02/17). Written consent was sought from every study respondent who participated in the study.

\section{Consent to Publish}

Study participants consented to the study findings being disseminated including publishing in scientific and peer review journals. However, this study does not contain any information that can traced to study respondents because individual details, images or videos have not been included.

\section{Availability of Data and Materials}

The datasets used and/or analysed during the current study are available from the corresponding author on reasonable request.

\section{Funding}

This research did not receive any grant from funding agencies in the public, commercial, or not-for-profit sectors.

\section{Authors' Contribution}

MA designed and conceptualized the study with support from RA. VFD and MA analysed qualitative data, with KA analysing the quantitative data under the supervision of RA. VFD and RA read the draft manuscript and revised it for important intellectual content. All authors read and approved the final manuscript.

\section{Acknowledgements}

Sincere gratitude goes to all the study respondents who agreed to participate in the study, especially those who shared their experiences of stigma and discrimination.

\section{Conflicts of Interest}

The authors declare no conflicts of interest regarding the publication of this paper.

\section{References}

[1] World Health Organisation (2017) Obesity and Overweight. WHO. http://www.who.int/mediacentre/factsheets/fs311/en/ 
[2] Swinburn, B.A., Sacks, G., Hall, K.D., McPherson, K., Finegood, D.T., Moodie, M.L., et al. (2011) The Global Obesity Pandemic: Shaped by Global Drivers and Local Environments. The Lancet, 378, 804-814. https://doi.org/10.1016/S0140-6736(11)60813-1

[3] Ells, L.J., Hancock, C., Copley, V.R., Mead, E., Dinsdale, H., Kinra, S., et al. (2015) Prevalence of Severe Childhood Obesity in England: 2006-2013. Archives of Disease in Childhood, 100, 631-636. https://doi.org/10.1136/archdischild-2014-307036

[4] Ogden, C.L., Carroll, M.D., Fryar, C.D. and Flegal, K.M. (2015) Prevalence of Obesity among Adults and Youth: United States, 2011-2014. NCHS Data Brief, No. 219, 1-8. http://www.ncbi.nlm.nih.gov/pubmed/26633046

[5] Utter, J., Denny, S., Teevale, T., Peiris-John, R. and Dyson, B. (2015) Prevalence and Recent Trends in Overweight, Obesity, and Severe Obesity among New Zealand Adolescents. Childhood Obesity, 11, 585-5859. https://doi.org/10.1089/chi.2014.0151

[6] Ekpenyong, B.C. (2013) Urbanization Drift and Obesity Epidemic in Sub-Saharan Africa: A Review of the Situation in Nigeria. European Journal of Sustainable Development, 2, 141-164. https://doi.org/10.14207/ejsd.2013.v2n2p141

[7] Pinhas-Hamiel, O. and Sabin, M. (2013) Obesity in Developing Countries. In: Practical Pediatric Endocrinology in a Limited Resource Setting, Springer, New York, 135-158. https://doi.org/10.1016/B978-0-12-407822-2.00006-2

[8] Ellulu, M., Abed, Y., Rahmat, A., Ranneh, Y. and Ali, F. (2014) Epidemiology of Obesity in Developing Countries: Challenges and Prevention. Global Epidemic $O b$ esity, 2, 2. http://www.hoajonline.com/obesity/2052-5966/2/2 https://doi.org/10.7243/2052-5966-2-2

[9] Agyemang, C., Boatemaa, S., Frempong, G.A. and de-Graft Aikins, A. (2015) Obesity in Sub-Saharan Africa. In: Metabolic Syndrome, Springer, New York, 1-13. http://link.springer.com/10.1007/978-3-319-12125-3_5-1 https://doi.org/10.1007/978-3-319-12125-3_5-1

[10] Ghana Statistical Service (2015) Ghana Demographic Health Survey. Ghana Statistical Service, 530. https://dhsprogram.com/pubs/pdf/FR307/FR307.pdf

[11] Benkeser, R.M., Biritwum, R. and Hill, A.G. (2012) Prevalence of Overweight and Obesity and Perception of Healthy and Desirable Body Size in Urban, Ghanaian Women. Ghana Medical Journal, 46, 66-75.

http://www.pubmedcentral.nih.gov/articlerender.fcgi?artid=PMC3426384

[12] Pereko, K.K.A., Setorglo, J., Owusu, W.B., Tiweh, J.M. and Achampong, E.K. (2013) Overnutrition and Associated Factors among Adults Aged 20 Years and above in Fishing Communities in the Urban Cape Coast Metropolis, Ghana. Public Health Nutrition, 16, 591-595. https://doi.org/10.1017/S1368980012002698

[13] Tomiyama, A.J. (2014) Weight Stigma Is Stressful. A Review of Evidence for the Cyclic Obesity/Weight-Based Stigma Model. Appetite, 82, 8-15. https://doi.org/10.1016/j.appet.2014.06.108

[14] Schafer, M.H. and Ferraro, K.F. (2011) The Stigma of Obesity: Does Perceived Weight Discrimination Affect Identity and Physical Health? Social Psychology Quarterly, 74, 76-97. https://doi.org/10.1177/0190272511398197

[15] Puhl, R.M. and Heuer, C.A. (2010) Obesity Stigma: Important Considerations for Public Health. American Journal of Public Health, 100, 1019-1028. https://doi.org/10.2105/AJPH.2009.159491

[16] Puhl, R. and Suh, Y. (2015) Health Consequences of Weight Stigma: Implications for Obesity Prevention and Treatment. Current Obesity Reports, 4, 182-190. 
https://doi.org/10.1007/s13679-015-0153-Z

[17] Puhl, R. and Suh, Y. (2015) Stigma and Eating and Weight Disorders. Current Psychiatry Reports, 17, 552. https://doi.org/10.1007/s11920-015-0552-6

[18] Mooney, S.J. and El-Sayed, A.M. (2016) Stigma and the Etiology of Depression among the Obese: An Agent-Based Exploration. Social Science \& Medicine, 148, 1-7. https://doi.org/10.1016/j.socscimed.2015.11.020

[19] Latner, J.D., Stunkard, A.J. and Terence Wilson, G. (2005) Stigmatized Students: Age, Sex, and Ethnicity Effects in the Stigmatization of Obesity. Obesity Research, 13, 1226-1231. https://doi.org/10.1038/oby.2005.145

[20] Aryeetey, R.N.O. (2016) Perceptions and Experiences of Overweight among Women in the Ga East District, Ghana. Frontiers in Nutrition, 3, 1-8.

http://journal.frontiersin.org/Article/10.3389/fnut.2016.00013/abstract https://doi.org/10.3389/fnut.2016.00013

[21] Madrigal, H., Sánchez-Villegas, A., Martínez-González, M.A., Kearney, J., Gibney, M.J., De Irala, J., et al. (2000) Underestimation of Body Mass Index through Perceived Body Image as Compared to Self-Reported Body Mass Index in the European Union. Public Health, 114, 468-473. https://doi.org/10.1016/S0033-3506(00)00390-5

[22] Ver Ploeg, M.L., Chang, H.H. and Lin, B.H. (2008) Over, under, or about Right: Misperceptions of Body Weight among Food Stamp Participants. Obesity, 16, 2120-2125. https://doi.org/10.1038/oby.2008.306

[23] Cheung, P.C.H., Ip, P.L.S., Lam, S.T. and Bibby, H. (2007) A Study on Body Weight Perception and Weight Control Behaviours among Adolescents in Hong Kong. Hong Kong Medical Journal, 13, 16-21.

[24] Lemon, S.C., Rosal, M.C., Zapka, J., Borg, A. and Andersen, V. (2009) Contributions of Weight Perceptions to Weight Loss Attempts: Differences by Body Mass Index and Gender. Body Image, 6, 90-96. https://doi.org/10.1016/j.bodyim.2008.11.004

[25] Amoah, A.G. (2003) Sociodemographic Variations in Obesity among Ghanaian adults. Public Health Nutrition, 6, 751-757.

http://www.journals.cambridge.org/abstract_S1368980003001010 https://doi.org/10.1079/PHN2003506

[26] Prentice, A.M. (2006) The Emerging Epidemic of Obesity in Developing Countries. International Journal of Epidemiology, 35, 93-99.

https://doi.org/10.1093/ije/dyi272

[27] Faber, M. and Kruger, H.S. (2005) Dietary Intake, Perceptions Regarding Body Weight, and Attitudes toward Weight Control of Normal Weight, Overweight, and Obese Black Females in a Rural Village in South Africa. Ethnicity \& Disease, 15, 238-245.

[28] Sikorski, C., Luppa, M., Kaiser, M., Glaesmer, H., Schomerus, G., König, H.H. and Riedel-Heller, S.G. (2011) The Stigma of Obesity in the General Public and Its Implications for Public Health: A Systematic Review. BMC Public Health, 11, 661. http://www.embase.com/search/results?subaction=viewrecord\&from=export\&id=L $\underline{560063565}$ https://doi.org/10.1186/1471-2458-11-661

[29] Gonçalves, H., González, D.A., Araújo, C.P., Muniz, L., Tavares, P., Assunção, M.C., et al. (2012) Adolescents' Perception of Causes of Obesity: Unhealthy Lifestyles or Heritage? Journal of Adolescent Health, 51, S46-S52. https://doi.org/10.1016/j.jadohealth.2012.08.015 


\section{List of Abbreviations}

Body Mass Index: BMI

Ghana Health Service: GHS

Ghana Demographic and Health Survey: GDHS

In-Depth Interview: IDI

Junior High School: JHS

Senior High School: SHS

World Health Organization: WHO 